\title{
EVALUATION OF HOTEL EMPLOYEES' SATISFACTION USING UGC (USER GENERATED CONTENT)
}

\author{
Borovčanin Dušan ${ }^{1 *}$, \\ Kilibarda Nataša', \\ Milošević Miloš², \\ Knežević Miroslav ${ }^{1}$ \\ ${ }^{1}$ Faculty of Tourism and Hospitality \\ Management, \\ Singidunum University, \\ Belgrade, Serbia \\ ${ }^{2}$ Faculty of Physical Education and Sport \\ Management, \\ Singidunum University, \\ Belgrade, Serbia
}

\begin{abstract}
:
Job satisfaction is correlated with employees on job performance, guest satisfaction and implicitly with financial performance of a hotel. Previous studies showed that employees' satisfaction when published online can influence guests booking intentions. We argue that it can influence and that it should be used to facilitate the human resource management process and prevent high turnover rates which are characteristic for hospitality. User generated content created a space for hotel employees to share their satisfaction/dissatisfaction online with thousands of other jobseekers. This giant database could be used to improve working conditions, increase job satisfaction, and consequentially increase performance and guest satisfaction. This paper presents initial results from data collected from one of the most visited websites in the world glassdoor.com. In total, primary findings from more than 10.000 workers reviews were presented. Results show that culture and values and career opportunities are ranked as top variables that contribute to the overall job satisfaction. In addition, these two variables showed strong correlation with rating of senior management. This could be understood that employees their career opportunities and culture and values that prevail in organisation significantly associate with senior management.
\end{abstract}

\section{Keywords:}

job satisfaction, hotel employees, user generated content.

\section{INTRODUCTION}

Satisfied employees in a hotel, tend to provide a better service quality to a customer as they feel more enthusiastic and inspired with their job [1]. Apart from the fact that satisfied employees provide better service, they also show a higher intention to stay in the company [2] This is extremely important in hospitality as it records a high employee turnover rate across the industry. There are estimates that an average turnover of frontline employees in a year in hospitality moves around 65\% [3]. This should not be that surprising if we know that tourism is distinguished by poor working conditions for employees, which logically lead to high turnover rates [4]. However, high turnover rates are certainly not desirable to top management. It is not only a time-consuming process,
Correspondence:

Borovčanin Dušan

e-mail:

dborovcanin@singidunum.ac.rs 
but a very costly one as well. There were several attempts from academics to estimate the cost of employee turnover in a hotel. A study from Wasmuth and Davis from 1983 estimated that each incident of an employee turnover costs around 2,500 \$ [5]. A more recent study from Simons and Hinkin estimated even greater costs of employee turnover per incident (around 5,000\$) in their research [6]. Even though there are limitations in both studies, it is clear that hospitality faces a serious problem regarding employee turnover, which, as previously stated, is directly linked with employee satisfaction i.e. dissatisfaction at work.

Yet, employee satisfaction doesn't reflect only on retention rates. Many academics demonstrated that a satisfied employee performs better in the workplace as well i.e. that employee satisfaction is positively correlated with employee performance [7]-[9]. As Guest points out, employees' linkage with performance is the most common thing researched by many academics in the domain of HR [10].

Finally, employee satisfaction is set to be indirectly correlated with financial performance having customer satisfaction as mediator [11], [12]. Therefore, employee satisfaction sets to be one of the crucial factors in terms of successful hotel managing nowadays as it affects customer satisfaction, employee performance and finally financial results.

\section{LITERATURE REVIEW}

Many academics worldwide explored the topics covering employees' satisfaction. The pioneer work in this field may be traced back to almost a century ago, i.e. to prof. Fritz Roethlisberger. He developed a series of experiments in Western Electric Company in which more than 20,000 employees took part. A broad correlation between working conditions, motivation, incentives, organizational structure and performance was discovered [13]. Despite the fact that the conclusions sparked off many debates, its significance was so immense that Rust et al. highlighted that there had been over 5,000 studies on employee satisfaction prior to 1995 [14]. However, despite the tremendous effort, academics have not reached an agreement about what the most important factors that influence employee satisfaction are. One of the reasons for it is, as Lester points out, the number of variables that needs to be taken into consideration when one discusses employee satisfaction [15]. Simply put, employees are human beings, and they differ very much at many different levels, thus the idea about finding one perfect recipe for employee satisfaction which may be applicable on every organization is perhaps too optimistic.

Yet, some considerable efforts have been made, as in the study done by Cotton and Tuttle. They performed a meta-analysis in order to determine the most significant variables that lead to employee satisfaction or dissatisfaction which ultimately led to employee turnover [16]. Loveman analysed employee satisfaction and service profit chain in the retail banking sector [17]. Yee et al. explored employee satisfaction in high contact service industries [12]. However, most of the research conducted until recently hasn't involved hotel employees exclusively.

In the meantime, tourism and hospitality emerged as independent scientific disciplines and academics started to dig into the differences between hospitality and other industries. Finding the differences in hospitality is significant as it is fast and a vibrant, growing industry, globally speaking [18]. Moreover, repeating the experiments and research similar to prof. Roethlisberger would cause enormous costs and require significant resources. In addition, the working environment in hospitality is changing rapidly, therefore managers need a quick and efficient tool to access the job satisfaction of their employees. With the development of new technology and mass use of user generated content, this process could be facilitated much more efficiently.

\section{USER GENERATED CONTENT AND WORKER WORD OF MOUTH}

Since 2006, there was a major shift looking at the way media content has been produced [19]. Regular people became the online content creators, and most importantly they created the content everyone was interested to look at. There are several major reasons why UGC (User Generated Content) had such a strong impact in the world. Firstly, it is inexpensive and, in most cases, even free, since people usually create content at no charge [20]. Secondly, for content consumers information they consume is perceived as more relevant, and they tend to show higher rates of trust [21]-[23] .

UGC is a big resource of data which travellers and employees in hospitality leave on the Internet. In hospitality, there is a growing interest in using UGC in order to determine and gain insights into research problems which were not clearly understood by conventional methods [12, p. 200], [24] 
While most of the previous studies analysed UGC from the demands side (large guest reviews on the Internet distribution systems such as booking.com, Expedia or even social media) little has been analysed using UGC from hotel employees. This should not be surprising as UGC posted by hotel employees almost didn't exist in the way it could be analysed. However, its significance was recently demonstrated in a study undertaken by Gonzalez and Gidumal, using the experiment as a method. It showed that customers' booking intentions can be seriously affected if they find any kind of injustice towards employees on the Internet [25]. For that reason, employers nowadays, apart from all the other factors, need to pay attention to what their employees share and post online as it can affect their reputation and even sales. Not only do employees make posts about their job satisfaction on their private platforms, but also do so on specialized platforms for integrated exchange of opinions which were created with a view to having a centralized database containing employees' reviews of their employers. This data is quite relevant and important for job seekers, but it also serves as a unique database for research as well. Considering that this has been a rising phenomenon, Gonzalez and Gidumal even invented the term weWOM which stands for "Worker eWOM". Before internet and platforms containing UGC, the process of finding information about prospective employer was quite demanding. Job seekers often found out most of the information about prospective employers, only after they started working [25].

At the moment, one of the best online sources for weWOM internationally is the website www.glassdoor.com. To add to the relevance of the source, Glassdoor contains the information from over 600,000 companies worldwide, while studies from web traffic ranked it among the first 800 websites searched online in the world [25], [26]. Even tough Glassdoor offers significant amount of information that primary of interest to jobseekers, it may offer valuable information for hotel managers as well. Managers can gain insight in what drives the overall satisfaction of their employees. In addition, hotel managers could use UGC platforms to gain knowledge and differentiate their job offerings towards potential candidates as well as towards their current employees in accordance with their attitudes presented online.

In order to gain insight in what drives employee satisfaction in corporate hotel chains, in this paper we decided to look into the data publicly available from Glassdoor.com. The dataset downloaded from Glassdoor included 10.207 valid reviews from hotel employees. Research findings are presented below.

\section{RESEARCH FINDINGS}

Research sample included ratings and reviews from the employees of 8 international corporate hotel chains that were ranked in the top 20 biggest hotel companies in 2018 according to the [27]. The selected hotel companies operate with over 4,000,000 hotel rooms worldwide and hire over 500,000 employees globally [27], [28]. In total employee ratings from 2719 hotels worldwide were evaluated. Hotels data were collected during the period of May 2008 up to June 2018. The sample included employees from six continents, and properties ranging from the small ones, with 10 rooms, to the big ones with a 1,000room capacity. The positions held by the employees who left their reviews ranged from that of a Housekeeper to General Manager i.e. from the top management to an entry level. Every respondent left answers about 5 specific variables in total followed with additional information and open comments and recommendations for management. Our research focused only on quantitative marks related with 5 variables. These 5 variables were: work life balance, culture and values, career opportunities, compensations and benefits and senior management. The respondents rated their satisfaction on a 5-point scale.

The results from descriptive statistics and correlation matrix are presented in tables 1 and 2. Before running the Pearson correlation, normality distribution of each variable was checked. Two variables were slightly skewed towards higher rating points, yet not significantly to be excluded from performing the analysis.

The reviews analysed in this paper rated their satisfaction on a 5-point scale (1- lowest satisfaction, 5 highest satisfaction). In table 1 results show that employees were the most satisfied with culture and values in their respective organisations followed with career opportunities and compensations and benefits. Contrary they rated the lowest on average the senior management and work-life balance.

Table 1. - Descriptive statistics

\begin{tabular}{cccccccc}
\hline & N & Min & Max & \multicolumn{2}{c}{ Mean } & std & var \\
\cline { 2 - 8 } & Sta & Sta & Sta & Sta. & Std. er. & Sta & Sta \\
\hline WLB & 11837 & 1 & 5 & 3,31 &, 012 & 1,29 & 1,66 \\
\hline CV & 10419 & 1 & 5 & 3,72 &, 013 & 1,31 & 1,72 \\
\hline CO & 11868 & 1 & 5 & 3,46 &, 012 & 1,29 & 1,66 \\
\hline CB & 11840 & 1 & 5 & 3,35 &, 011 & 1,23 & 1,51 \\
\hline SM & 11643 & 1 & 5 & 3,21 &, 013 & 1,37 & 1,87 \\
\hline
\end{tabular}

Valid 10207

Legend: WLB- Work life balance; CV - Culture \& Values; CO- Career opportunities; CB - Compensation \& Benefits; SM - Senior Management, Sta - Statistic, Std. er. - standard error, var-variance, $\mathrm{N}$ - number 
Results from table 1 are in accordance with previous findings which demonstrated that financial benefits are not still the top priority for hotel employees, as well as that career opportunities are among the highly appreciated job satisfaction factors within generations Y and Z [29], [30]. Furthermore, correlation matrix (table 2) shows that there is a moderate, positive correlation among all variables except culture and values and career opportunities with senior management. Each correlation was proved statistically significant at the level of 0.95 .

Table 2. - Correlation matrix

\begin{tabular}{|c|c|c|c|c|c|c|}
\hline & & WB & $\mathrm{CV}$ & $\mathrm{CO}$ & $\mathrm{CB}$ & SM \\
\hline \multirow{2}{*}{ WB } & $\mathrm{r}$ & & .57 & .46 & .49 & .58 \\
\hline & $\mathrm{p}$ & & .00 & .00 & .00 & .00 \\
\hline \multirow{2}{*}{ CV } & $\mathrm{r}$ & & & .65 & .55 & .72 \\
\hline & $\mathrm{p}$ & & & .00 & .00 & .00 \\
\hline \multirow{2}{*}{$\mathrm{CO}$} & $r$ & & & & .59 & .64 \\
\hline & $\mathrm{p}$ & & & & .00 & .00 \\
\hline \multirow{2}{*}{$\mathrm{CB}$} & $\mathrm{r}$ & & & & & .52 \\
\hline & $\mathrm{p}$ & & & & & .00 \\
\hline
\end{tabular}

Legend: WLB- Work life balance; CV - Culture \& Values; CO- Career opportunities; CB - Compensation \& Benefits; SM - Senior Management; $r$ - Pearson correlation; $\mathrm{p}$ - significance (2-tailed)

This could be understood that the highest rated variables on average (Culture and values and Career opportunities) are in strong correlation with the actions taken from senior management. Further analysis could demonstrate if these findings were under the influence of younger workers. Finally, results from table 2 also prove that overall job satisfaction is influenced by multiple factors which are all positively corelated.

\section{CONCLUSION}

This paper analysed job satisfaction of corporate hotel employees using workers reviews left on UGC website. Over 10.000 worker reviews from 8 hotel chains were analysed. The results showed that non-financial factors such as culture and values and career opportunities remain the top factors that contribute to the overall job satisfaction, which is in accordance with previous recent findings. In addition, the results from correlation matrix showed that these two variables had strong correlation with senior management. This could be understood that employees consider that the culture and values in an organisation as well as their career opportunities are dominantly influenced by senior management.
The importance of hotel employees' satisfaction and the impact it has on hotel performance has already been demonstrated multiple times. Yet hotel industry remains distinguished by poor working conditions and high turnover rates. We argue that UGC could be used by hotel managers to facilitate the process of job satisfaction analysis. WeWOM was already proven to influence booking intentions of potential guests, and we argue it could be used to offer better working conditions and to prevent a very costly process of turnover in hospitality.

Further analysis should look into differences among hotel scales, market where hotels operate as well as the difference in rating according to the job title of worker i.e. if it is service line, middle management or top management level of employee.

\section{REFERENCES}

[1] H. Kong, C. Cheung, and H. Song, "From hotel career management to employees' career satisfaction: The mediating effect of career competency," Int. J. Hosp. Manag., vol. 31, no. 1, pp. 76-85, Mar. 2012, doi: 10.1016/j.ijhm.2011.03.002.

[2] C.-F. Chiang, K.-J. Back, and D. D. Canter, "The Impact of Employee Training on Job Satisfaction and Intention to Stay in the Hotel Industry," J. Hum. Resour. Hosp. Tour., vol. 4, no. 2, pp. 99-118, Dec. 2005, doi: 10.1300/J171v04n02_06.

[3] L. Myers, "News from Cornell's Center for Hospitality Research: Free Web-based management tool helps hotels and restaurants weigh employee turnover cost," Cornell Chronicle, Jul. 19, 2005. http://news.cornell. edu/stories/2005/07/new-tool-helps-hotels-weighcost-employee-turnover (accessed Jul. 18, 2019).

[4] T. Baum, "Human resources in tourism: Still waiting for change," Tour. Manag., vol. 28, no. 6, pp. 1383-1399, Dec. 2007, doi: 10.1016/j.tourman.2007.04.005.

[5] W. Wasmuth and S. Davis, "Why Employees Leave -," Cornell Hosp. Q., vol. 24, no. 1, pp. 11-18, 1983, doi: $10.1177 / 001088048302400103$.

[6] T. Simons and T. Hinkin, "The Effect of Employee Turnover on Hotel Profits: A Test Across Multiple Hotels," Artic. Chapters, Aug. 2001, [Online]. Available: https://scholarship.sha.cornell.edu/articles/446.

[7] J. K. Harter, F. L. Schmidt, and T. L. Hayes, "Business-unit-level relationship between employee satisfaction, employee engagement, and business outcomes: A meta-analysis.," J. Appl. Psychol., vol. 87, no. 2, pp. 268-279, 2002, doi: 10.1037//00219010.87.2.268. 
[8] M. M. Petty, G. W. McGee, and J. W. Cavender, "A Meta-Analysis of the Relationships between Individual Job Satisfaction and Individual Performance," Acad. Manage. Rev., vol. 9, no. 4, p. 712, Oct. 1984, doi: 10.2307/258493.

[9] Y. Li and S. (Sam) Huang, "Hospitality service climate, employee service orientation, career aspiration and performance: A moderated mediation model," Int. J. Hosp. Manag., vol. 67, pp. 24-32, Oct. 2017, doi: 10.1016/j.ijhm.2017.07.012.

[10] D. E. Guest, "Perspectives on the Study of Work-life Balance," Soc. Sci. Inf., vol. 41, no. 2, pp. 255-279, Jun. 2002, doi: 10.1177/0539018402041002005.

[11] C. G. Chi and D. Gursoy, "Employee satisfaction, customer satisfaction, and financial performance: An empirical examination," Int. J. Hosp. Manag., vol. 28, no. 2, pp. 245-253, Jun. 2009, doi: 10.1016/j. ijhm.2008.08.003.

[12] R. W. Y. Yee, A. C. L. Yeung, and T. C. E. Cheng, "The impact of employee satisfaction on quality and profitability in high-contact service industries," $J$. Oper. Manag., vol. 26, no. 5, pp. 651-668, Sep. 2008, doi: 10.1016/j.jom.2008.01.001.

[13] F. J. Roethlisberger, W. J. Dickson, H. A. Wright, C. H. Pforzheimer, and Western Electric Company, Management and the worker: an account of a research program conducted by the Western Electric Company, Hawthorne Works, Chicago. Cambridge, Mass.: Harvard University Press, 1939.

[14] R. T. Rust, G. L. Stewart, H. Miller, and D. Pielack, "The satisfaction and retention of frontline employees: A customer satisfaction measurement approach," Int. J. Serv. Ind. Manag., vol. 7, no. 5, pp. 62-80, Dec. 1996, doi: 10.1108/09564239610149966.

[15] P. E. Lester, "Development and Factor Analysis of the Teacher Job Satisfaction Questionnaire (TJSQ)," Educ. Psychol. Meas., vol. 47, no. 1, pp. 223-233, Mar. 1987, doi: 10.1177/0013164487471031.

[16] J. L. Cotton and J. M. Tuttle, "Employee Turnover: A Meta-Analysis and Review with Implications for Research," Acad. Manage. Rev., vol. 11, no. 1, pp. 55-70, Jan. 1986, doi: 10.5465/amr.1986.4282625.

[17] G. W. Loveman, "Employee Satisfaction, Customer Loyalty, and Financial Performance: An Empirical Examination of the Service Profit Chain in Retail Banking," J. Serv. Res., vol. 1, no. 1, pp. 18-31, Aug. 1998, doi: 10.1177/109467059800100103.

[18] R. Howard and M. Fishbin, "Global hospitality insights," Ernst \& Young, 2016.

[19] M. Lavoie and G. Rodríguez, "The Economic Impact of Professional Teams on Monthly Hotel Occupancy Rates of Canadian Cities: A Box-Jenkins Approach," J. Sports Econ., vol. 6, no. 3, pp. 314324, Aug. 2005, doi: 10.1177/1527002504268614.
[20] T. Daugherty, M. S. Eastin, and L. Bright, "Exploring Consumer Motivations for Creating User-Generated Content," J. Interact. Advert., vol. 8, no. 2, pp. 16-25, Mar. 2008, doi: 10.1080/15252019.2008.10722139.

[21] Stephen Burgess, Carmine Sellitto, Carmen Cox, and Jeremy Buultjens, "USER-GENERATED CONTENT (UGC) IN TOURISM: BENEFITS AND CONCERNS OF ONLINE CONSUMERS," in $17^{\text {th }}$ European Conference on Information Systems, VErona, pp. 1-14.

[22] J. Rupert Hills and G. Cairncross, "Small accommodation providers and UGC web sites: perceptions and practices," Int. J. Contemp. Hosp. Manag., vol. 23, no. 1, pp. 26-43, Jan. 2011, doi: $10.1108 / 09596111111101652$.

[23] R. Williams, T. van der Wiele, J. van Iwaarden, and S. Eldridge, "The importance of user-generated content: the case of hotels," TQM J., vol. 22, no. 2, pp. 117-128, Jan. 2010, doi: 10.1108/17542731011024246.

[24] Y. Yang, H. Zhang, and X. Chen, "Coronavirus pandemic and tourism: Dynamic stochastic general equilibrium modeling of infectious disease outbreak," Ann. Tour. Res., p. 102913, Apr. 2020, doi: 10.1016/j.annals.2020.102913.

[25] S. Melián-González and J. Bulchand-Gidumal, "Extending the scope of hotel client reactions to employee injustice: Hotel employer reviews on the Internet," Int. J. Hosp. Manag., vol. 63, pp. 93-100, May 2017, doi: 10.1016/j.ijhm.2017.03.003.

[26] Glassdoor, "Glassdoor Job Search | Find the job that fits your life," Glassdoor, 2020. https://www.glassdoor.com/index.htm (accessed Sep. 10, 2020).

[27] J. Weinstein, “Special report 325," HOTELS' magazine, Special report, 2019.

[28] Forbes, "America's Best Large Employers," Forbes, 2019. https://www.forbes.com/best-large-employers/ (accessed Oct. 19, 2019).

[29] D. Gursoy, C. G.-Q. Chi, and E. Karadag, "Generational differences in work values and attitudes among frontline and service contact employees," Int. J. Hosp. Manag., vol. 32, pp. 40-48, Mar. 2013, doi: 10.1016/j.ijhm.2012.04.002.

[30] M. Alvesson and S. Sveningsson, Changing organizational culture: cultural change work in progress. New York: Routledge, 2008. 